\title{
PENGEMBANGAN SISTEM PENGELOLAAN DATA KUALITAS AIR LIMBAH DOMESTIK PERKOTAAN
}

\author{
Heru Dwi Wahjono \\ Pusat Teknologi Lingkungan, BPP Teknologi \\ J. MH. Thamrin No. 8 Jakarta Pusat
}

\begin{abstract}
One of the activities undertaken within the framework of environmental sanitation management by the government is to publish a variety of regulations governing the wastewater disposal problem. Sources of pollution of the most dominant in urban areas are domestic wastewater. Government institutions through BPLHD have conducted regular monitoring of river water quality in Jakarta. Management of water quality data from domestic waste sources is needed to control river water pollution. This requires data management system of urban domestic waste water quality. In this article will be discussed the development of data management systems for domestic waste water quality with reference to the current applicable regulations.
\end{abstract}

Key words : water quality database, domestic waste water quality

\section{PENDAHULUAN}

\subsection{Latar Belakang}

Penurunan kualitas air di kota-kota besar seperti Jakarta tidak lagi hanya disebabkan oleh industri yang ada di sekitar kota ini, namun banyak disebabkan pula oleh kegiatan rumah tangga, perkantoran dan kegiatan domestik lainnya yang ada di dalam kota. Tahun 2010 oleh studi JICA diperkirakan $74 \%$ pencemaran sungai yang ada di Jakarta disebabkan oleh limbah domestik (1).

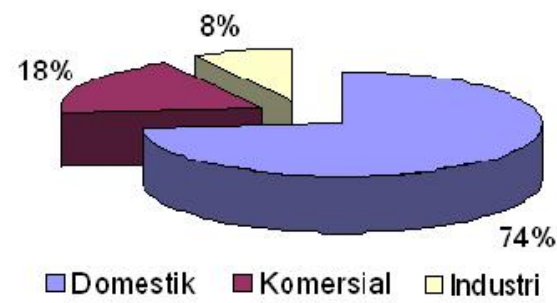

\section{Gambar 1. Grafik prosentase sumber pencemaran air sungai di Jakarta}

Kegiatan pemantuan kualitas air limbah yang telah dilakukan oleh instansi pemerintah secara rutin kebanyakan berasal dari sumbersumber pencemar yang ada di industri. Sedangkan air limbah di lingkungan domestik belum dilakukan pengelolaan data dengan baik. Baru pada tahun 2005 pemerintah memandang perlu untuk melakukan pengelolaan air limbah domestik. Pada tahun ini pemerintah telah menerbitkan Peraturan Gubernur Provinsi Daerah Khusus lbukota Jakarta Nomor 122 Tahun 2005 Tentang Pengelolaan Air Limbah Domestik Di Provinsi Daerah Khusus Ibukota Jakarta. Dalam peraturan ini ditetapkan beberapa parameter yang harus dipenuhi oleh air limbah domestik yang diperbolehklan dibuang ke saluran umum.

\subsection{Tujuan dan Sasaran}

Tujuan kegiatan ini adalah melakukan pengembangan sistem pengelolaan data kualitas air limbah domestik di perkotaan. Adapun sasarannya adalah :

- Diperoleh rancangan teknis database kualitas air limbah domestik.

- Diperoleh perangkat lunak database kualtias air limbah domestik.

\subsection{Manfaat yang Diharapkan}

Manfaat yang diharapkan dari kegiatan pengembangan sistem pengelolaan data kualitas air limbah domestik ini adalah :

- Memberi masukan tentang perlunya dilakukan pengelolaan data kualitas air limbah domestik perkotaan.

- Tersusunnya rancangan sistem pengelolaan data untuk air limbah domestik perkotaan.

- Terbangunnya software pengelolaan data yang untuk air limbah domestik perkotaan sesuai peraturan yang ada.

\subsection{Lingkup Kegiatan}

Lingkup kegiatan pengembangan sistem pengelolaan data kualitas air limbah domestik adalah sebagai berikut :

1. Identifikasi kebijakan mengenai parameter dan baku mutu air limbah domestik.

2. Survei data dan format laporan yang telah dilakukan oleh instansi terkait seperti kantor BPLHD DKI Jakarta 
3. Perancangan sistem database dan bentuk tampilan yang akan dipakai dalam menyusun struktur data.

4. Pengembangan perangkat lunak basis data kualitas air limbah domestik

\section{METODOLOGI}

Metodologi yang digunakan dalam melaksanakan kegiatan pengembangan sistem pengelolaan datanya adalah menggunakan Software Development Live Cycle (SLDC) yang artinya siklus hidup pengembangan software, yang memiliki tahapan sebagai berikut: (2)
a. Analisa Sistem
b. Disain Awal Database
c. Detail Disain Database
d. Pengembangan
e. Pengujian Software
f. Evaluasi

\section{PERGUB. PROVINSI DKI JAKARTA MENGENAI AIR LIMBAH DOMESTIK}

Sebagai tindak lanjut keseriusan Pemerintah Daerah Khusus lbukota Jakarta menangani air limbah domestik di kelima wilayah DKI Jakarta, Gubernur DKI Jakarta telah mengeluarkan Peraturan Gubernur Provinsi Daerah Khusus Ibukota Jakarta Nomor 122 Tahun 2005 Tentang Pengelolaan Air Limbah Domestik Di Provinsi Daerah Khusus Ibukota Jakarta. Peraturan Gubernur ini dikeluarkan bertujuan untuk mencegah dan menanggulangi pencemaran tanah dan air tanah akibat pembuangan air limbah domestik yang tidak memenuhi Baku Mutu Air Limbah (3).

$\mathrm{Di}$ dalam peraturan ini didefinisikan beberapa hal, yakni :

1. Pengelolaan Air Limbah Domestik adalah upaya memperbaiki kualitas air yang berasal dari kegiatan rumah tangga/perkantoran sehingga layak untuk dibuang ke saluran kota/drainase.

2. Baku mutu limbah cair adalah batas kadar dan jumlah unsur pencemar yang ditenggang adanya dalam limbah cair untuk dibuang dari satu jenis kegiatan tertentu.

3. Pencemaran air adalah masuk atau dimasukkan mahluk, zat, energi dan komponen lain ke dalam air oleh kegiatan manusia, sehingga kualitas air turun sampai ke tingkat tertentu sehingga tidak sesuai dengan peruntukkannya.

4. Air Limbah adalah air yang berasal dari sisa kegiatan proses produksi dan usaha lainnya yang tidak dimanfaatkan kembali.

5. Air limbah domestik adalah air limbah yang berasal dari kegiatan rumah tangga, perumahan, rumah susun, apartemen, perkantoran, rumah dan kantor rumah dan toko, rumah sakit, mall, pasar swalayan, balai pertemuan, hotel, industri, sekolah, baik berupa grey water (air bekas) ataupun black water (air kotor/tinja).

Selain memberikan batasan-batasan mengenai pengelolaan air limbah domestik, di dalam peraturan gubernur ini juga diberikan beberapa contoh model instalasi pengolahan air limbah yang dapat diterapkan oleh masyarakat mulai dari kapasitas pengelolaan yang kecil sampai dengan kapasitas pengelolaan dalam skala besar.

Baku mutu air limbah domestik telah yang diatur dalam peraturan gubernur ini adalah untuk paramter-paremeter $\mathrm{pH}, \mathrm{KMNO} 4$, TSS, Amoniak, Minyak dan Lemak, Senyawa Biru Metilen, COD dan BOD. Adapun nilai baku mutu air limbah domestik dibagi menjadi dua kelompok, yaitu individual / rumah tangga dan komunal. Nilai baku mutu untuk masing-masing kelompok ditunjukkan dalam tabel 1 di bawah ini.

Tabel 1. Baku Mutu Limbah Cair Domestik (3)

\begin{tabular}{|l|c|c|c|}
\hline PARA-METER & UNIT & $\begin{array}{c}\text { INDIVIDUAL I } \\
\text { RMH TANGGA }\end{array}$ & KOMUNAL \\
\hline $\mathrm{pH}$ & - & $6-9$ & $6-9$ \\
\hline $\mathrm{KMnO} 4$ & $\mathrm{Mg} / \mathrm{L}$ & 85 & 85 \\
\hline $\mathrm{TSS}$ & $\mathrm{Mg} / \mathrm{L}$ & 50 & 50 \\
\hline Amoniak & $\mathrm{Mg} / \mathrm{L}$ & 10 & 10 \\
\hline Minyak \& Lemak & $\mathrm{Mg} / \mathrm{L}$ & 10 & 20 \\
\hline $\begin{array}{l}\text { Senyawa Biru } \\
\text { Metilen }\end{array}$ & $\mathrm{Mg} / \mathrm{L}$ & 2 & 2 \\
\hline $\mathrm{COD}$ & $\mathrm{Mg} / \mathrm{L}$ & 100 & 80 \\
\hline $\mathrm{BOD}$ & $\mathrm{Mg} / \mathrm{L}$ & 75 & 50 \\
\hline
\end{tabular}

\section{RANCANGAN SISTEM DATABASE}

Sistem database kualitas air limbah domestik dibangun dengan membuat tabel inti, yaitu tabel kualitas air dengan beberapa tabel pendukung, yaitu tabel jenis data, tabel jenis industri, tabel jenis sampling, tabel lokasi sumber limbah dan tabel password. Selain itu dibuat juga tabel kerja/query untuk mempermudah pengguna dalam pengoperasian data, yaitu query domestik, query lokasi, dan query password. Untuk pelaporan disusun format laporan yang dapat digunakan untuk menampilkan data baku mutu, data kualitas air dalam bentuk angka dan grafik serta data lokasi sumber limbah.

Dari parameter pemantauan kualitas air limbah yang diwajibkan oleh peraturan gubernur, maka susunan struktur tabel inti, tabel data kualitas air limbah domestik dapat dilihat seperti pada tabel 2 di bawah ini.

Tabel 2. Struktur tabel data kualitas 
air limbah domestik

\begin{tabular}{|c|c|c|}
\hline Nama Field & Tipe & Keterangan \\
\hline RecordID & Number & Nomor Identifikasi Record \\
\hline NomorSampling & Text & $\begin{array}{l}\text { Nomor Identifikasi } \\
\text { Pengambilan Sampling }\end{array}$ \\
\hline KodeLokasi & Number & $\begin{array}{l}\text { Nomor Identifikasi Lokasi } \\
\text { Pengambilan Sampling }\end{array}$ \\
\hline JenisData & Text & $\begin{array}{l}\text { Jenis Data Yang Dimasuk } \\
\text { kan (Baku Mutu / Hasil Uji) }\end{array}$ \\
\hline TanggalAmbil & Date/Time & $\begin{array}{l}\text { Tanggal Pengambilan } \\
\text { Sampling Data }\end{array}$ \\
\hline WaktuAmbil & Date/Time & $\begin{array}{l}\text { Waktu Pengambilan } \\
\text { Sampling Data }\end{array}$ \\
\hline JenisContoh & Number & $\begin{array}{l}\text { Jenis Air Yang Diambil } \\
\text { Sebagai Sampling Data }\end{array}$ \\
\hline TanggalKirim & Date/Time & \begin{tabular}{lcc} 
Tanggal & \multicolumn{2}{c}{ Pengiriman } \\
Sampling $\quad$ Data & $\mathrm{Ke}$ \\
Laboratorium Analisa & \\
\end{tabular} \\
\hline TanggalSelesai & Date/Time & $\begin{array}{lr}\text { Tanggal } & \text { Selesai } \\
\text { Penerimaan } & \text { Hasil } \\
\text { Pemeriksaan Laboratorium }\end{array}$ \\
\hline PengambilSampling & Date/Time & $\begin{array}{l}\text { Nama Instansi Yang } \\
\text { Mengambil Sampling Data }\end{array}$ \\
\hline Keperluan & Date/Time & $\begin{array}{l}\text { Maksud Keperluan } \\
\text { Pengambilan Sampling }\end{array}$ \\
\hline $\mathrm{Ph}$ & Number & $\begin{array}{l}\text { Tingkat } \\
\text { Keasaman/Kebasaan }(\mathrm{pH})\end{array}$ \\
\hline Kmno4 & Number & $\begin{array}{ll}\text { Kandungan } & \text { Senyawa } \\
\text { Organic KMN04 } & \end{array}$ \\
\hline Tss & Number & $\begin{array}{ll}\text { Jumlah Zat } & \text { Padat/Residu } \\
\text { Tersuspensi } & \text { (Total } \\
\text { Suspended Substances) }\end{array}$ \\
\hline AmoniakBebas & Number & $\begin{array}{l}\text { Kandungan Amoniak Bebas } \\
\text { (Free Amminiac/NH3) }\end{array}$ \\
\hline Oil & Number & $\begin{array}{l}\text { Kandungan Minyak dan } \\
\text { Lemak (Oil and Grease) }\end{array}$ \\
\hline Methyl & Number & $\begin{array}{l}\text { Kandungan Deterjen I } \\
\text { Senyawa Methylene Blue } \\
\text { Active Substance }\end{array}$ \\
\hline Cod & Number & $\begin{array}{l}\text { Chemical Oxygen Demand } \\
\text { (COD) }\end{array}$ \\
\hline Bod & Number & $\begin{array}{ll}\text { Biochemical } & \text { Oxygen } \\
\text { Demand (BOD) } & \\
\end{array}$ \\
\hline Debit & Number & Debit Aliran Air (Liter/Detik) \\
\hline Sistem & Text & $\begin{array}{l}\text { Sistem IPAL : Individual / } \\
\text { Rumah Tangga / Komunal }\end{array}$ \\
\hline SumberData & Text & $\begin{array}{l}\text { Sumber Pengambilan Data } \\
\text { Kualitas Air }\end{array}$ \\
\hline Keterangan & Memo & $\begin{array}{l}\text { Keterangan Lain Mengenai } \\
\text { Kualitas Air }\end{array}$ \\
\hline
\end{tabular}

Rancangan relasi tabel inti, tabel data kualitas air limbah domestik dengan tabel-tabel pendukung lainnya dapat dilihat seperti pada gambar 2 di bawah ini.

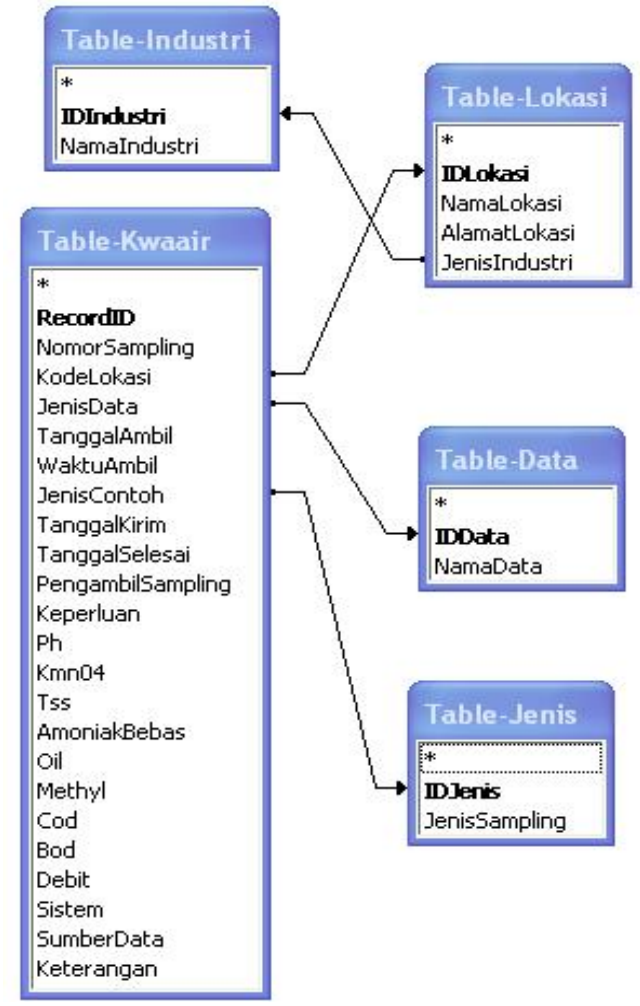

Gambar 2. Rancangan struktur dan relasi tabel data kualitas air limbah domestik ${ }^{(5)}$

Selanjutnya dari rancangan relasi beberapa tabel di atas disusun tabel kerja/query menggunakan bahasa SQL (Structured Query Language), seperti contoh berikut :

SELECT [Table-Kwaair].JenisData, [Table-

Kwaair].RecordID, [Table-Kwaair].NomorSampling, [TableData].NamaData, [Table-Kwaair].KodeLokasi, [TableLokasi].NamaLokasi, [Table-Lokasi].AlamatLokasi, [TableLokasi].JenisIndustri, [Table-Industri].Namalndustri, [TableKwaair].PengambilSampling, [Table-Kwaair].JenisContoh, [Table-Jenis].JenisSampling, [Table-Kwaair].TanggalAmbil, [Table-Kwaair].WaktuAmbil, [Table-Kwaair].TanggalKirim, [Table-Kwaair].TanggalSelesai, [Table-Kwaair].Keperluan, [Table-Kwaair].Ph, [Table-Kwaair].Kmn04, [TableKwaair].Tss, [Table-Kwaair].AmoniakBebas, [TableKwaair].Oil, [Table-Kwaair].Methyl, [Table-Kwaair].Cod, [Table-Kwaair].Bod, [Table-Kwaair].Debit, [TableKwaair].Sistem, [Table-Kwaair].SumberData, [TableKwaair].Keterangan

FROM [Table-Industri] RIGHT JOIN ([Table-Lokasi] RIGHT JOIN ([Table-Jenis] RIGHT JOIN ([Table-Data] RIGHT JOIN [Table-Kwaair] ON [Table-Data].IDData = [TableKwaair].JenisData) ON [Table-Jenis].IDJenis = [TableKwaair].JenisContoh) ON [Table-Lokasi].IDLokasi = [TableKwaair].KodeLokasi) ON [Table-Industri].IDIndustri = [TableLokasi].JenisIndustri

WHERE (([Table-Kwaair].JenisData)="BMDOMESTIK" Or ([Table-Kwaair].JenisData)="DTDOMESTIK")) ORDER BY [Table-Kwaair].JenisData, [TableKwaair].NomorSampling; 
Agar data kualitas air yang dimasukkan dapat langsung diidentifikasikan sebagai data yang melebihi baku mutu atau tidak, maka perlu dibuatkan kondisi dalam bentuk kode program seperti contoh di bawah ini, dimana setiap parameter ditentukan nilai baku mutunya sesuai peraturan yang berlaku.

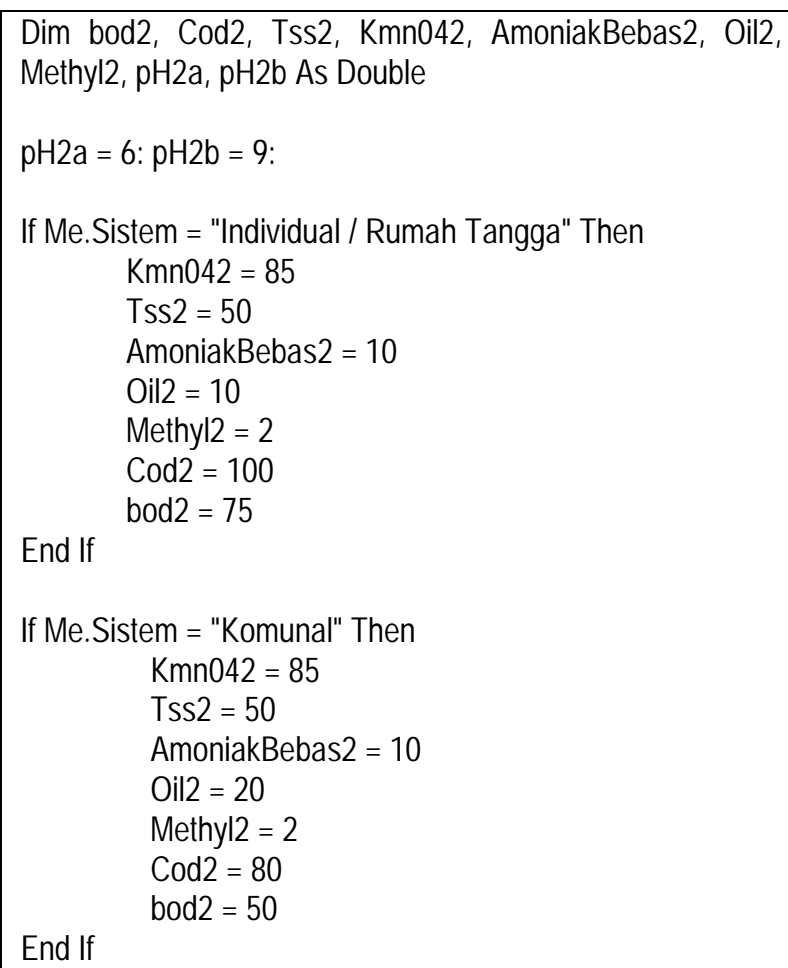

\subsection{Rancang Bangun Sistem Software}

Pengembangan sistem software untuk pengelolaan data kualitas air limbah domestik dilakukan dengan membuat rancangan user interface pengisian data sesuai dengan tabel data dan tabel kerja yang ada. Selain itu juga disusun format laporan untuk menampilkan data monitoring kualitas air limbah domestik. Rancangan sistem pengoperasiannya seperti pada gambar 3 .

Sistem perangkat lunak yang dikembangkan terdiri dari beberapa modul. Masing-masing modul dikembangkan dan diintergrasikan ke dalam satu menu pengoperasian sedemikian rupa, sehingga dapat dengan mudah digunakan oleh pengguna perangkat lunak ini.

\section{Modul Menu Utama}

Modul ini akan muncul pertama kali saat pengguna berhasil login ke dalam sistem dengan otoritas aksesnya. Menu utama berisi ikon untuk mengaktifkan modul yang ada di dalamnya, yaitu : Input Data, View Data, Lokasi, Password, Regulasi, dan Baku Mutu.

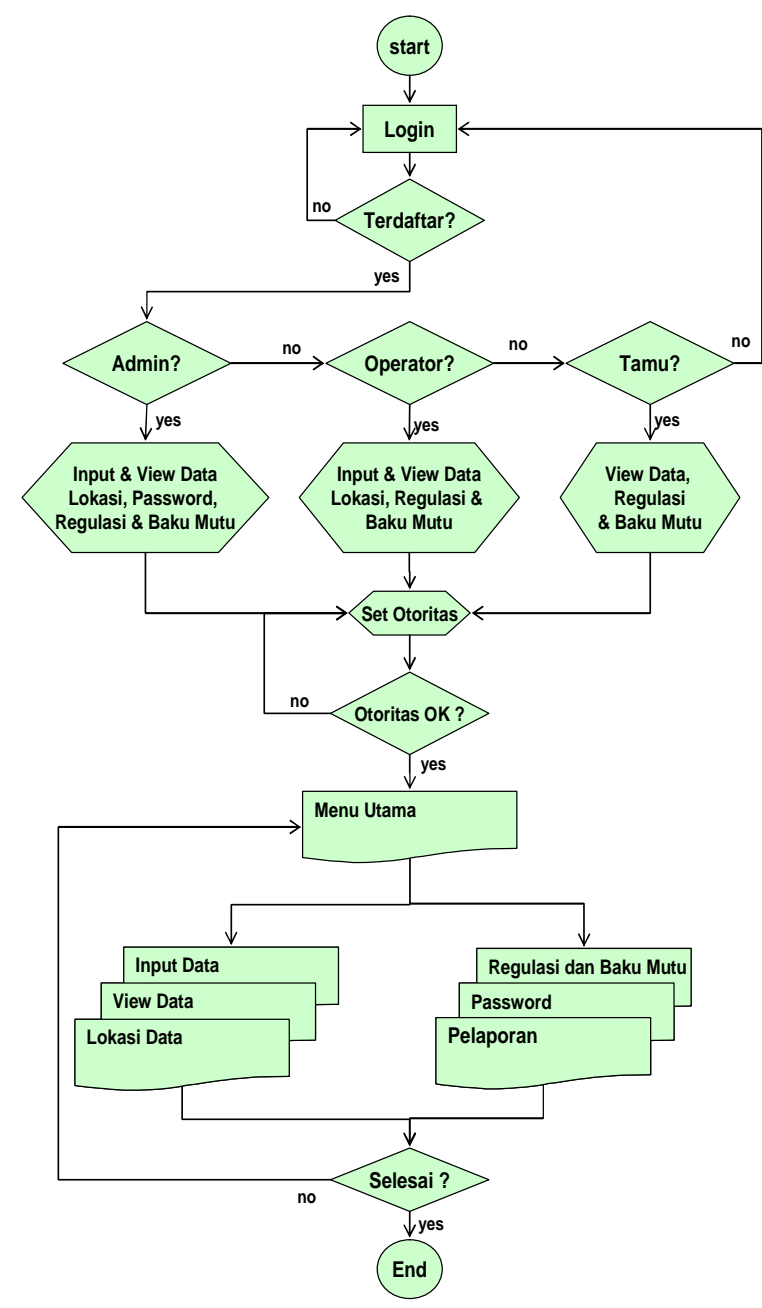

Gambar 3. Diagram Alir Proses Pengoperasian Software ${ }^{(5)}$

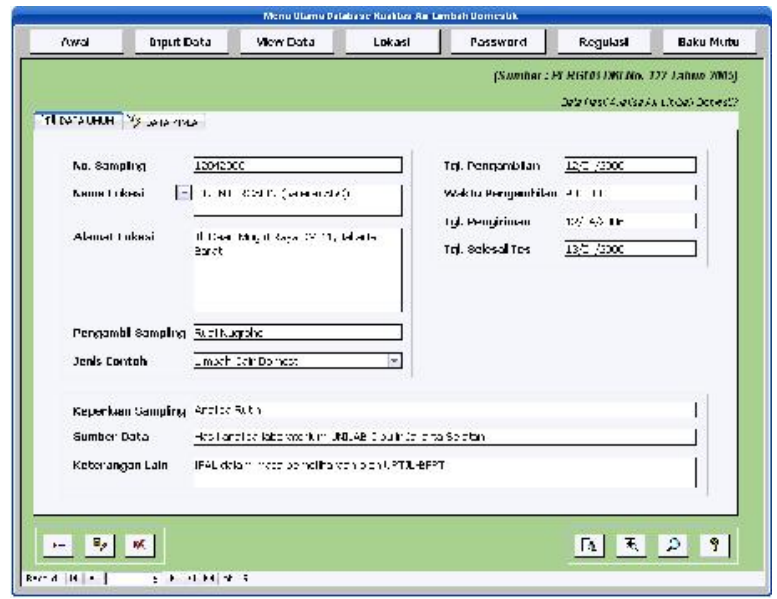

Gambar 4. Window menu utama

\section{Modul Input Data}

Modul ini digunakan untuk memasukkan dan menyunting data kualitas air limbah domestik. Modul ini memiliki dua tab control, yakni Data Umum dan Data Kimia. 


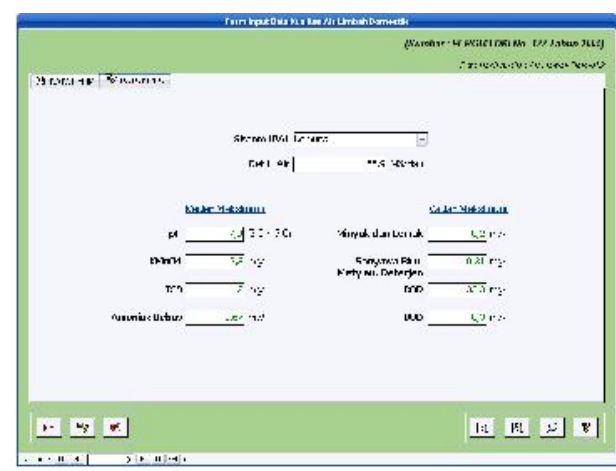

Gambar 5. Window input data

\section{Modul View Data}

Modul ini digunakan untuk menelusuri dan menampilkan kembali data-data kualitas air limbah domestik yang telah disimpan beberapa waktu yang lalu. Pengguna harus memilih data lokasi dan periode pencatatan serta parameter ukur yang akan ditampilkan grafiknya. Data yang ditampilkan akan dibandingkan dengan baku mutu yang ada.

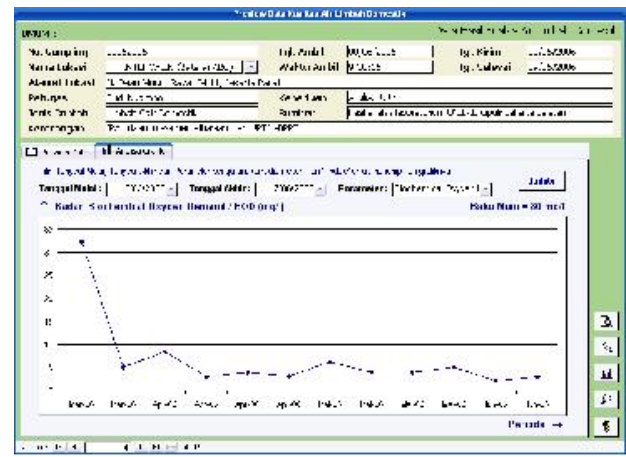

Gambar 6. Window View Data

\section{Modul Lokasi}

Modul ini digunakan untuk menyunting data informasi umum mengenai lokasi monitoring.

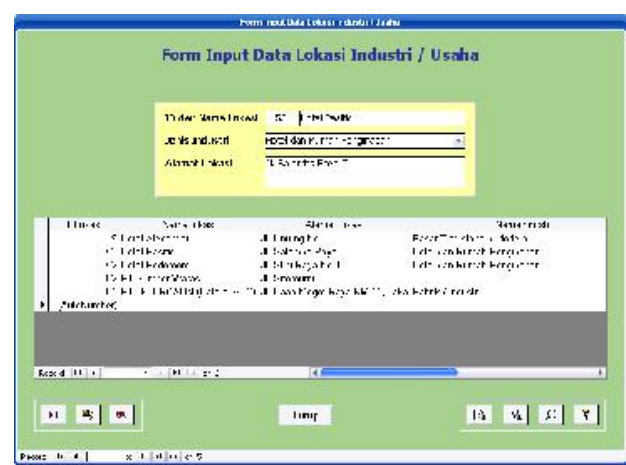

Gambar 7. Window lokasi

\section{Modul Pengguna}

Modul ini digunakan untuk menyunting data pengguna sistem software dan hanya dapat dibuka oleh pengguna dengan otoritas akses sebagai administrator.

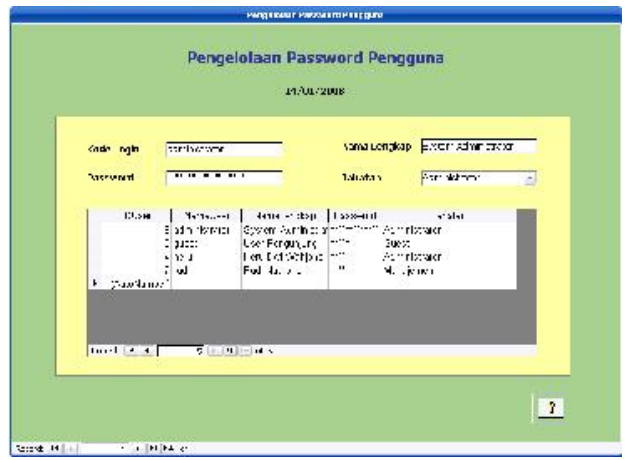

Gambar 8. Window pengguna

\subsection{Modul Pendukung}

Untuk melengkapi kebutuhan pengguna dalam mengoperasikan sistem software nantinya telah disiapkan modul-modul pendukung, yakni :

\section{Modul Pelaporan}

Modul ini berisi rancangan berbagai bentuk dokumentasi pelaporan, antara lain : laporan ringkas, laporan rinci, laporan lengkap dan laporan satuan data.

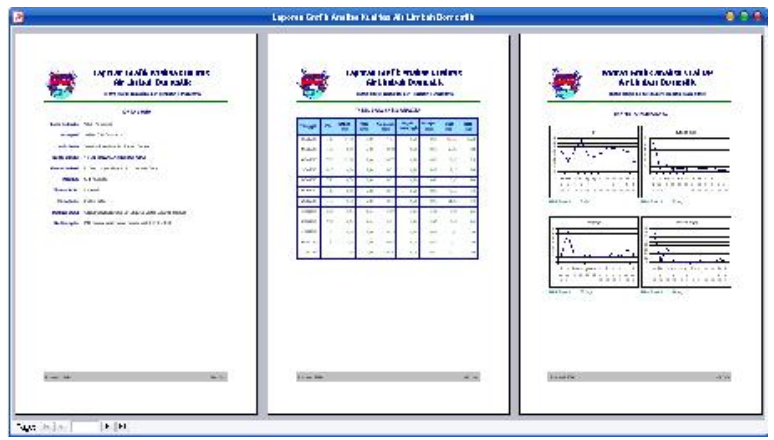

Gambar 9. Window pelaporan

2. Modul Regulasi dan Baku Mutu

Modul ini berisi informasi peraturan perundangan mengenai baku mutu kualitas air limbah domestik.

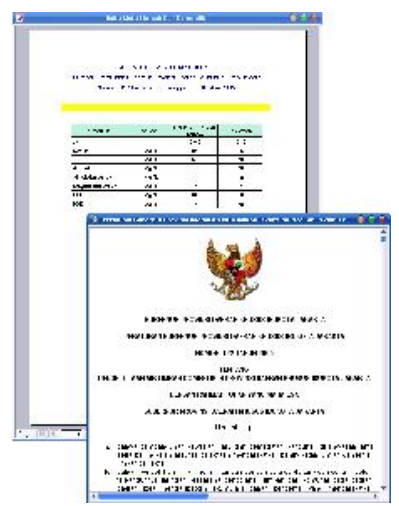

Gambar 10 . Window regulasi dan baku mutu 


\section{Modul Petunjuk Pengoperasian}

Modul ini merupakan dokumentasi elektronik petunjuk pengoperasian sistem software secara keseluruhan.

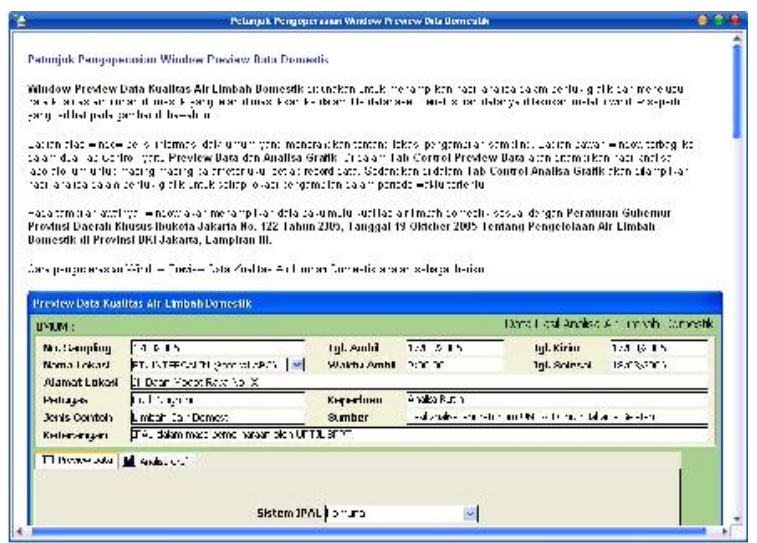

Gambar 11. Window petunjuk pengoperasian

\subsection{Sistem Pengamanan Data}

Sistem pengamanan data dirancang agar setiap pengguna memiliki otoritas akses yang berbeda-beda yang dapat dikelompokkan ke dalam tiga kelompok otoritas, yaitu :

1. Administrator : memiliki semua otoritas untuk mengelola seluruh sistem.

2. Operator : memiliki otoritas memasukkan data, menelusuri dan melihat laporan data.

3. Tamu : hanya memiliki otoritas menelusuri data.

Adapun otoritas akses ketiga kelompok pengguna tersebut adalah sebagai berikut :

1. Administrator : Input Data, Lihat Data, Laporan Data, dan Sistem Administrasi

2. Operator : Input Data, Lihat Data, Laporan Data

3. Tamu : Lihat Data

\section{KESIMPULAN}

Selama proses rancang bangun sistem pengelolaan data air limbah domestik perkotaan yang terdiri dari kegiatan perancangan sistem database dan pengembangan antar muka perangkat lunaknya, dapat ditarik beberapa sebagai kesimpulan antara lain :

1. Peraturan perundangan yang ada mengatur baku mutu air limbah domestik dengan membagi baku mutu menjadi dua jenis baku mutu sesuai dengan cara pengolahan air limbah domestik. Untuk itu dalam software pengguna harus memilih salah satu jenis baku mutu yang akan digunakan untuk membandingkan data hasil pengujian analisa laboratoriumnya.

2. Agar data yang telah dimasukkan dapat langsung dianalisa, maka data yang telah diketikkan ke dalam form input di layar monitor langsung dibandingkan dengan data baku mutu kualitas air limbah dan menampilkannya dengan warna hijau jika data yang dimasukkan tidak melampaui baku mutu dan berwarna merah jika telah melampaui nilai baku mutu.

3. Kedua fitur dalam nomor 1 dan 2 di atas dapat diaplikasikan dengan menggunakan fungsi 'If condition Then [statements] [Else elsestatements]" dalam kode program, sehinga fitur-fitur tersebut dapat dipenuhi.

4. Untuk memudahkan user dalam penggunaan data secara bersama, perlu disiapkan suatu tool untuk melakukan ekspor data yang telah ada di dalam database ke dalam format lain misalnya ASCII TXT atau format MS Excel.

5. Agar aplikasi yang dihasilkan (".mde) dapat langsung dijalankan tanpa melalui program database MS. Access, perlu diintegrasikan dengan program Access Runtime(4), sehingga selain dapat menghemat memori komputer juga dapat menghemat waktu pada saat program aplikasi dijalankan.

\section{DAFTAR PUSTAKA}

1. JICA (1990), The Study On Urban Drainage and Waste Water Disposal Project In The City Of Jakarta.

2. Curtis G. (1995), Bussiness Information System $2^{\text {nd }}$ Edition. Wokingham, England: Addison Wesley

3. Peraturan Gubernur Provinsi Daerah Khusus Ibukota Jakarta Nomor 122 Tahun 2005 Tentang Pengelolaan Air Limbah Domestik Di Provinsi Daerah Khusus Ibukota Jakarta.

4. Anonymous, Protect Your MS Access DB (http://www.adit.co.uk/html/sql_for_access.ht $m)$ : A.D.I.T Software 2008

5. EKM (2008), Petunjuk Operasional Software Sistem Informasi Kualitas Lingkungan Modul Database Kualitas Air 